\section{TREATMENT OF CHOLERA}

\author{
ON BOARD THE
}

\section{CIRCASSIAN, CONVICT SHIP.**}

Sin, - I beg leave to transmit the cases of Nartin Kelly and Ann MI.Namara, persons embarked on board this ship, which although not so severe as some commonly met with, still, I am of opinion, had they not been early under treatment, might ultimately have proved so.

My treatment of diarrhoa is simply this. I bleed them to not above sixteen ounces, on the very first application to me, which has generully been in the early stage of the disease, owing to the very strict orders which I have given to that effect. I then immediately commence giring three grains of calomel, and half a grain of opium every four hours, until the gums becin to be sensibly affected, and the dejections, which at first are of a very light colour, and in most instances watery, have assumed a healtby appearance.

I then give them a little rhubarb and magnesia in peppermint water; and of the twenty-nine cases which I bave had (exclusive of the four of cholera) four have this day been discharged to duty, and the others are all in a most favourable state; indeed a great part of them are only continued in the Return to owing the soreness of their mouths, and the danger of relapse from imprudences in their diet.

The ship is tolerably well ventilated, and the prisons, hospitals, and barracks, are daily fumigated and sprinkled with chloride of lime, and the people liept in the greatest possible state of cleanliness.

$$
\text { I am, Sir, }
$$

Your much obliged and very humble servant,

Circnssian Convict-Ship,

Wr. Porteous.

Standgate Creek, Aug. $29,1892$.

To W. Maclean, Esq.

Report of two Cases of Cholera on board of the Circassian Convict Ship off Woolwich.

CASE $r$.

Ann M'Namara (soldier's wife), aged 18, was atlacked at eleven p. m., on the 18th of August, with vomiting, griping, and purging, followed towards the morning by cramps in the abdominal muscles, and excessive thirst.

* Communicated by the Central Board of Health.
She says that she romited four times, but the purging was almost incessant until eight o'clock this morning (19th), and she does not know the nature of the dejections farther than that they were watery, but the matter ejected from the stomach tasted bitter. At eight o'clock sle complained to me, and was then suffering severely from cramp in the abdomind muscles; countenance anxious but not shruuk; pulse 76 , of good strength. The romiting had ceased, but she had been purged about a quarter of an hour previously.

I gave her immediately twenty-fire drons of laudanum in halt a wineglassful of brandy, and bottles of hot water were applied to the abdomen, after which she hal no more purging or vomiting. The crame left her in a short time, when she fell asleep, and continued so for about an hour.

At one p. m., she had a copious loose stool, resembling very thin rice-water, without any griping. She had great thirst and vertigo, and had occasional slight twitches of cramp in the abdominal muscles during the day, for which she took sir or seven drops of laudanum in a very small quantity of brandy, three or four times, and the hot water was continued.

At ten a. m., she began taking four grains of calomel and half a grain of opium every four hours, and warm gruel was given for drink, which treatment was continued during the night.

Next morning she was much better; had slept a little; the pain had entirely left her; had had three or four loose dejections of the same nature as the one above men. tioned; and about two o'clock she voided urine for the first time for twenty-four hours. Pulse 80 .

The calomel and opium were continued throu hont the day, and she had two or three loose dejections, each succeediug one of more natural appearance; and on the morning of the 21st they were perfecty bealthy, and she rapidly recovered with out any other particular symptom.

CASE II.

Martin Kelly (soldier), aged 28, com. plained to me on the morning of the $23 \mathrm{~d}$ of August, of having been purged two or three times during the night without any griping. His dejections were described as bemg light coloured. He took three grains of calomel and half a grain of opium erer four hours during the day and throughou the night.

At noon on the $24 \mathrm{th}$, while sitting on th poop, he was suddenly seized with vertig and a sense of faintness, of which I $\mathrm{wa}$ almost immediately informed; and whe seen, he complained of excessive wrat ness and great nausea, but he had 
romited nor had he been purged since the / still purplish and cold; cramps not so ur. morning, and then only once, and once dur- gent; tongue no longer cold; slightly ing the night. His countenance was pale and crusted; vomiting quite as frequent and almost ghastly ; pulse weak, irregular, and copious. On the 8 th there was some imabout 80 , and his skin was covered with a provement, some warmth of skin, but no profuse cold perspiration.

I had him immediately conveyed to the hospital, and put to bed; bled lim to $3 x v i$; gase him twenty-five drops of lautanum in two ounces of brandy, and applied warmth to bis extremities.

He expressed himself immediately re. liered by the bleeding; the pulse became regular and full ; the cold perspiration was succeeded by a fine warm moisture, and he bad no farther unpleasant symptom.

The calomel and opium were continued every four hours, until the morning of the 26th, when his gums were slightly affected, and the dejections, which at first were loose and very light coloured, became quite natural. He then took a dose of rhubarb and magnesia, which operated, and without having any other particular symptom, be was this day discharged to duty.

W. Porteous,

Surgeon Superintendent.

Standgate Creek, Aug. 29, 1832. urine. On the $9 \mathrm{th}$, a slight tinge of bile in the evacuations; no urine; pulse returned, but beating slowly. On the 10th, motions decidedly bilious, and the last feculent. Skin warm and pulse better; no urine till the 11th, from which time he gradually improved; was out on the $16 \mathrm{tb}$, and resumed his labour on the $24 t h$, having had scarcely any consecutive fever.

The treatment was as follows :-A mustard plaster was applied to the spine, from the occiput to the sacrum, and followed by a blister sprend on adhesive plaster. An enema of starch and laudanum was immediately administered, repeated in three hours, and then every twelve hours for four days; but after every loose motion, three-fourihs of a pint of starch alone were thrown up the rectum. No medicine of any kind, but cold water as much and as fre. quently as the patient desired.

A medical friend, who saw this case with me on the 11 th, afterwards treated a pulseless old man, atat. 70 , on the same plan, except giving 40 drops of laudanum in chalk mixture, and speedy recovery ensued; reaction being so decided as to al. low of bleeding.

I gave cold water ad libitum to the first IN THE COTLAPSE STAGE OF

MALIGNANT CHOLERA.

To the Members of the Central Board of Health, London.

Gentumen,-The perusal of Dr. Hard. wicke Shute's communications induces me to trinsmit an account of a most severe case successfully treated some weeks back almost on the same principles.

On the 6th August, at seven p.m., I visited a young man, retat. 20 , who was in the confirmed collapse stage of cholera, attended with the following symptoms :-General coldness and purplish colour of the skin, from every pore of which issued copious cold perspiration, or rather cold water; brenth and tongue cold, the latter feeling like a frog; no pulse at the wrist; cramps in almost every muscle, and the vomiting and purging of transparent fluid excessive; urine suppressed; the countenance, if at first in any degree shrunken, became in less than an hour completely collaped, and the roice decidedly a choieric whisper. On the 7 th the pulse had not returned, yet the diarrhoa was considerably checked, but an immoderate flow of urine for a short time was ebserved. The skin was dry, though patient I attended with cholera, and withdrew all stimulants, and succeeded; but many other remedies were also tried, and it was not till 1 lost two cases, and witnessed many deatlis under other plans, that in the cold stage $I$ adopted the simple method above detailed. Experience alone can decide, whether the counter-irritation be or be not essential in addition to the cold water. I am, Gentlemen,

Your obedient servant, Joseph B. WhITINa,

King's Lynn, Sept. 2nd, 1832.

In premonitary eases, the astringent and opiate plan recommended to the medical practitioners of this town by my brother Dr. Whiting, has been marked by the most decided success in arresting the progress of the disease, of which there have certuinly been three, if not five importations. 